\title{
Motivations in Open Source Software Communities: The Mediating Role of Effort Intensity and Goal Commitment
}

\author{
Weiling Ke and Ping Zhang \\ ABSTRACT: As a community-based innovation, the open source software (OSS) develop- \\ ment phenomenon has received great attention from researchers and practitioners. Under- \\ standing the factors that affect the involvement and contributions of participants in OSS \\ projects is of significance to facilitate project success. This paper investigates the effects of \\ motivation on participant performance in OSS projects, drawing upon self-determination \\ theory to examine how task effort (i.e., effort intensity and goal commitment) mediates \\ the relationships between a spectrum of motivations and individual performance. The \\ research model is supported by survey data from 204 participants in OSS projects. The \\ theoretical contributions and managerial implications are discussed.
}

KEY WORDS AND PHRASES: Motivation, open source software (OSS), performance, task effort.

As a community-based innovation, open source software (OSS) projects such as Linux and Apache are exemplars of organizational models for innovation and product development [24,73]. The distinction of OSS projects is that their participants, most likely volunteers, collaborate with one other and continuously improve the software programs through the Internet [40]. The participants also provide mundane services that are critical for the viability of the communities, such as documentation and helping new members. Since there are no traditional organizational structures of control, the viability and sustainability of OSS projects rely on participants' self-managing contributions $[66,67,73,74]$. Studying the factors that lead individuals to participate and remain engaged in OSS projects helps us to understand the success of OSS projects [5].

A number of studies address such questions as "What factors drive participants to contribute to OSS communities?" and "How do OSS project groups keep participants engaged in the community?" (e.g., [5, 30, 31, 73, 80]). From the personal perspective, studies have found that participation in OSS projects is driven by intrinsic or extrinsic motivations [30, 38, 60]. From the social perspective, research has found that conviction of the ideology associated with OSS development and identification with OSS project groups serve as linchpins in enabling OSS efforts and success [5, 31, 39, 51, 66].

The extant literature only assesses the direct main effect of each of these four motivational factors on individual participation in or contribution to OSS projects (e.g., [30,60]). There is a lack of research examining the effect of motivation on participation outcomes such as performance. Performance is defined as the cognitive outcome of conducting a series of activities [78]. The viability and sustainability of OSS communities rely more on the outcomes than on the act of participating. Therefore, investigating how motivational factors affect task performance will provide practical guidelines for possible 
mechanisms that enhance the chance of project success. In addition, there is no prior study examining the effect of mediator variables on the relationships between motivational factors and performance in OSS projects. This lack of understanding of the black box may explain why some findings are mixed and even controversial. For example, Roberts, Hann, and Slaughter found that intrinsic motivation had no significant effect on participants' contribution levels, whereas Shah found that intrinsic motivation drove developers to remain engaged in the project $[60,63]$. Lakhani and Wolf also found evidence in favor of intrinsic motivation as the driving force [38]. Investigating what factors mediate the relationships between motivational factors and performance, and how they do this, may help to resolve the inconsistency of the existing research findings.

The present study attempts to address the shortfall in the literature by investigating the factors mediating the association of motivation and participant performance in OSS projects. In particular, it draws upon self-determination theory (SDT) to develop a research model. According to SDT, the abovementioned social motivational factors, namely social identification with the project group and the conviction of OSS ideology, are internalized extrinsic motivations $[19,61]$. Together with personal motivations (i.e., intrinsic and extrinsic motivation), they form a more comprehensive set of motivation types in OSS communities. Therefore, these four types of motivation are incorporated in the study.

SDT posits that motivation is an intention to act and therefore cannot lead to behavior outcomes directly. Instead, motivation is translated into participation outcomes, such as task performance, by means of effort expended on the task $[19,45,55]$. Following this notion, the study develops and tests a structural model in which task effort mediates the effects of motivation on participants' performance in OSS projects. In particular, it is expected that task effort, namely effort intensity and goal commitment, will mediate the motivationperformance relationship. Effort intensity refers to the amount of resources expended [34, 58, 75]. Goal commitment is defined as a person's persistence in reaching the goal [47]. Empirical data from individuals participating in OSS projects largely support the relationships among motivational factors, mediators, and task performance.

\section{Motivations in OSS Communities}

According to previous studies, participant motivation, as the driver for initial and continued engagement, effort, and contributions, plays a critical role in OSS project success $[30,31,60,63,73]$. In particular, researchers have found that the motivational factors in OSS communities include individuals' intrinsic and extrinsic motivation, social identification with OSS project groups, and conviction of the OSS movement ideology. The intrinsic motivation of OSS community participants includes enjoyment derived from the challenge of seeking solutions and learning programming [30, 31, 63]; their extrinsic motivation includes their personal software needs, career concerns, and reputations and status in the community $[24,29,37,59]$. The effect of intrinsic and extrinsic 
motivation on individual contributions to OSS communities has gained wide empirical support (e.g., [30, 31]).

Recent studies of OSS have found that OSS communities play a critical role in motivating developers to contribute to OSS projects (e.g., [5, 30, 38]). In particular, research has found that social identification with the community is an important factor leading the surveyed developers to contribute to OSS projects $[5,38]$. Social identification helps explain why individuals are willing to perform tasks that are mundane, time-consuming, and unlikely to garner prestige $[5,31,37]$. Examples of tasks of this type are providing unpaid assistance and advocacy to enlist and help new users, providing field support for other members of the group, and contributing one's own money to run advertisements for the group [5]. OSS research has also found that ideology associated with OSS development is an important motivator for individual contributions to OSS projects [5, 51, 67].

While studies on motivation in OSS communities advance our understanding of what mobilizes individuals to participate in and contribute to the development of public goods, they do not provide insights into how motivational factors lead to individual performance. This approach neither reflects the richness of motivation theories nor provides a good description or explanation of the relationships.

\section{Self-Determination Theory}

The topic of motivation plays a central role in the field of performance management-both practically and theoretically. While managers see motivation as an integral part of the performance equation at all levels, researchers regard it as a fundamental building block in the development of theories of effective management practice [65]. Indeed, motivation theories are widely used to study work performance and job satisfaction [48]. There are many definitions of motivation in the literature. For example, Atkinson defines motivation as "the contemporary (immediate) influence on direction, vigor and persistence of action" [4, p. 2], while Locke and Latham define motivation as "internal factors that impel action and the external factors that can act as inducements to action" [48, p. 388]. According to Pinder, motivation refers to "a set of energetic forces that originates both within as well as beyond an individual's being, to initiate work-related behavior, and to determine its form, direction, intensity, and duration" [56, p. 11]. All these definitions are principally concerned with factors or events that energize, channel, and sustain human behavior over time and eventually lead to task performance and well-being [47, 50, 65].

In the literature, many theories have been put forth to explain individual motivation [34,56]. For example, deriving from the early work of Lewin and Tolman, Vroom presented the first systematic formulation of expectancy theory $[42,70,75]$. Similarly, Locke and Latham proposed a theory of goal setting that links goal specificity, goal difficulty, and goal commitment to enhanced task performance [47]. Most of these theories make meaningful contributions to our understanding of what is obviously a complex process. However, with the exception of SDT, motivation theories treat motivation as a unitary 
concept $[19,53,61]$. Although these theories recognize variation in the degree of motivation, they do not acknowledge the different types of motivations. This becomes problematic when there are multiple types of motivation influencing individuals' action intentions (e.g., the OSS context in which intrinsic and extrinsic motivations, social identification, and ideology conviction all play a role in energizing participants).

Porter and Lawler first proposed a model of intrinsic and extrinsic motivations [58]. Intrinsic motivation involves doing an activity to satisfy some immediate personal need, and thus the activity "is valued for its own sake and appears to be sustained" [17, p. 105]. In other words, intrinsic motivation refers to the motivation to engage in work primarily for its own sake because the work itself is engaging, interesting, or in some way satisfying. Extrinsic motivation, in contrast, requires an instrumentality between the activity and some separable consequences. That is, extrinsic motivation is the motivation to work primarily in response to something apart from the work itself, such as reward or recognition or the dictates of others. Therefore, extrinsic motivation involves undertaking an activity to satisfy one's needs indirectly.

SDT further differentiates extrinsic motivation by using the concept of internalization $[18,19,61]$. Internalization refers to taking in a behavioral regulation and the value that underlies it. According to SDT, extrinsic motivation can vary in the degree to which it is externally regulated or internalized. Specifically, Deci and Ryan identified four different forms of extrinsically motivated behavior: external, introjected, identified, and integrated [19]. With an external motivation (i.e., extrinsic motivation, as in other motivation theories), an individual acts with the intention of obtaining a desired consequence or avoiding an undesired one, and so is energized into action only when the action is instrumental to those ends. For example, working to get a reward is considered extrinsic motivation. In contrast, when internalized, an individual takes in values and regulatory control, such that the external regulation of a behavior is transformed into an internal regulation and no longer requires the presence of an external contingency [53, 61]. Based on the degree to which an external regulation has been internalized, internalized motivation can be categorized as introjected, identified, or integrated [25, 61]. When introjected, one has taken in the regulation but has not accepted it as one's own. When identified, one feels greater freedom and volition because the behavior is more congruent with one's personal goals and identity. Social identification with the project group is an example of identified extrinsic motivation. When integrated, one has a full sense that the behavior is an integral part of who one is, that it emanates from one's sense of self and is thus self-determined. For example, an ideology conviction is a kind of integrated extrinsic motivation. Table 1 provides a mapping of motivations in OSS projects to the motivational categories suggested by SDT.

In addition, SDT, like other contemporary motivation theories, explicates how motivations affect behavior outcomes (e.g., task performance) by investigating the mediating effect of effort expended on the task. Motivations reflect intentions to act [19]. They are not actions that can lead to work outcomes directly; rather, they are translated into accomplished work by means of effort [55]. It is established that task effort consists of three components: goal 


\section{Motivation in} OSS communities

Extrinsic motivation

Social identification

Ideology conviction

Intrinsic motivation

\section{Motivation in SDT}

External motivation

Identified extrinsic motivation

Integrated extrinsic motivation

Intrinsic motivation

\section{Table 1. Mapping of Motivational Factors in OSS to Categories Suggested by SDT.}

commitment (or duration), effort intensity (or force), and direction [34]. Goal commitment is defined as "the determination to try for a goal and the persistence in pursuing it over time" [32]. Effort intensity refers to the amount of resources expended. That is, effort intensity refers to how hard a person tries to carry out a chosen behavior [34,78]. Task direction is a person's behavioral choice and is often measured as a choice between mutually exclusive courses of action [34].

\section{Research Hypotheses}

Drawing on motivation theories, and on self-determination theory in particular, the study developed a research model to investigate the black box of motivation's effects on participant performance in OSS projects. Figure 1 depicts the research model. Specifically, it depicts how the four motivations (i.e., intrinsic motivation, extrinsic motivation, social identification, and ideology conviction) lead to participant performance in OSS projects, with their effects being mediated by task effort (i.e., effort intensity and goal commitment). As mentioned above, motivational factors are not actions that can lead to work outcomes directly; rather, they are translated into accomplished work by means of effort [55]. In this study, performance is defined as the perceived outcome of an individual's behavior in an OSS project [54]. In addition to the four motivations, four factors are also considered as control variables that may have influence on the mediators.

Task effort consists of three components: goal commitment, effort intensity, and effort direction [34]. The model focuses on the first two dimensions of effort and leaves out effort direction. There are two reasons for this: First, effort intensity and goal commitment constitute the essence of working hard over time [12]. Second, individuals may participate in multiple OSS projects, and the study is interested in the projects to which they dedicate most of their effort (i.e., effort direction is to work most actively in an OSS project for each individual).

When effort intensity is high, the individual allocates a large portion of resources available to the task at hand and thus may achieve good performance [34]. In OSS communities, project goals are usually set by project core teams or initial software developers [51]. Although the content of goals varies across different OSS projects, the central component of all OSS project goals 


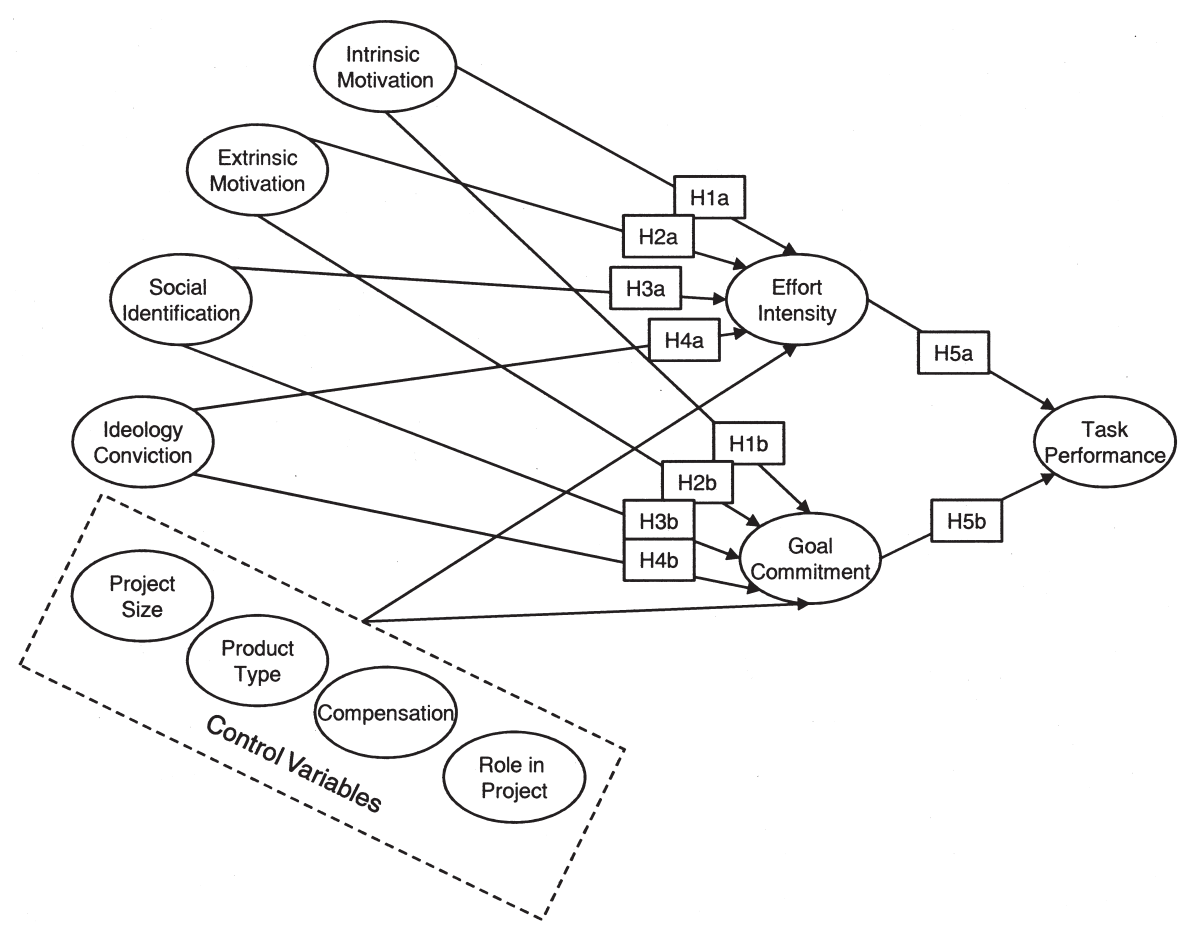

Figure 1. The Research Model

is the development of free software that meets user requirements [64]. Goal commitment is the binding of individuals to specific behavioral acts [62]. It manifests the extent to which the individual psychologically accepts the goal [47]. Therefore, an individual having a high level of goal commitment should persist in that effort and thus attain high performance [46].

Intrinsic motivation is a psychological force within an individual that determines the direction of the individual's behavior, level of effort, and level of persistence in the face of obstacles [34]. This force is derived from the individual's need for self-determination and competence [20]. At any time, the need that is the most intense is the one individuals will attempt to satisfy or to reduce through their behavior [77]. That is, behavior is, to a certain extent, ruled by psychological needs [18]. In OSS communities, individuals have the freedom to choose what to contribute and how to contribute [9]. In addition, OSS communities continuously improve their software, which challenges individuals cognitively and requires them to be creative. Further, all solutions to problems are transparent, which provides excellent opportunities for individuals to learn [59]. As such, developing OSS readily satisfies the need for self-determination and competence. Individuals with higher intrinsic motivation have more intense need and therefore tend to work more intensely on the OSS project.

Intrinsic motivation is expected to have a similar effect on goal commitment in OSS communities. The individual's need for competence and self- 
determination is consistent with the project goal of continuously improving the software to best meet user requirements. As long as the OSS project is ongoing, the project can keep the individual constantly challenged, learning, and enjoying the freedom to do what he or she likes to do. Indeed, the more complex and difficult the task, the more it may satisfy the individual's need for competence and make the individual more persistent [47]. Stated alternatively, intrinsic motivation energizes the individual to be more committed to the goal. Empirically, the effect of intrinsic motivation on individual OSS project participation has gained support from the several prior studies (e.g., $[31,63])$. Therefore,

\section{Hypothesis 1a: Intrinsic motivation positively affects an individual's effort intensity in OSS projects.}

Hypothesis 1b: Intrinsic motivation positively affects an individual's goal commitment in OSS projects.

Extrinsic motivation drives individuals to work hard on the project so that they can get the expected reward, such as future career opportunities and financial gains. Individuals tend to rationally evaluate various behaviors (e.g., work harder) and then choose the behaviors they believe will lead to their most valued rewards and outcomes (e.g., job opportunities) [75]. According to SDT, when rewards are performance-contingent, they increase the importance of doing well on a personal level and thus motivate individuals to work more intensively $[19,60,61]$. Therefore, a high level of extrinsic motivation is associated with a high level of effort intensity.

In the OSS context, participants can signal their ability to potential employers and gain status in the community [41,74]. These incentives are ego-enhancing and provide feelings of worth [60]. The positive relationship between extrinsic motivation and effort intensity is expected to remain valid in the OSS context.

The empirical findings of extrinsic motivation's effect on goal commitment in OSS communities are mixed. For example, some scholars have found that individuals with high extrinsic motivation had low goal commitment [63]. By contrast, other researchers found that extrinsic motivation made individuals remain engaged in the OSS community (e.g., [24, 29, 37, 59, 60]). According to motivation theories in general and SDT in particular, external incentives positively affect goal commitment $[19,45,75]$. The positive relationship between extrinsic motivation and goal commitment has gained strong support from empirical studies conducted in contexts other than OSS communities, although there are conflicting results in previous studies on OSS communities (e.g., $[49,52,79])$. Therefore,

\section{Hypothesis 2a: Extrinsic motivation positively affects an individual's effort intensity in OSS projects.}

Hypothesis 2b: Extrinsic motivation positively affects an individual's goal commitment in OSS projects. 
When individuals work in groups, their behavior is influenced by their social identification, in addition to their individual preferences and motives. In social settings, individuals tend to think of themselves and others in terms of particular group memberships [68,70]. Social identification is a process by which information about social groups is related to the self [21]. In particular, social identification leads individuals to demonstrate loyalty to the group and induces adherence to group norms - they perceive an interdependence between their individual outcomes and the group's collective outcomes, and have less individually instrumental considerations [1, 6]. Therefore, SDT suggests that social identification enables an individual to take in the regulatory control and voluntarily perform behaviors for the benefit of group members $[6,19,22]$.

This logic can be extended to the OSS context. Individuals who have a high level of identification with an OSS project group will perceive the collective goal as their own. In particular, as a member of the group, the individual's behavior is ruled by group norms - that is, reciprocity norms. So the individual is mobilized to expend intense effort on solving problems and contributing source code to support other participants, with trust in the others to do the same $[11,66]$. Moreover, the internalized collective goal will get the individual affectively involved in striving for goal attainment [1, 19]. As such, the individual will persistently work on the goal and overcome difficulties to attain the goal. Therefore,

Hypothesis 3a: Social identification with the group positively affects an individual's effort intensity in OSS projects.

Hypothesis 3b: Social identification with the group positively affects an individual's goal commitment in OSS projects.

Ideology is defined as "shared, relatively coherently interrelated sets of emotionally charged beliefs, values and norms that bind some people together and help them make sense of their worlds" [71, p. 33]. Ideology guides individuals in evaluating the legitimacy of their behavior and endorses relevant tasks with meaningfulness and significance [33]. An individual who identifies with an ideology will perceive the work aligned with this ideology as rewarding and worthwhile. Therefore, ideology conviction plays a motivating role in energizing the individual's' effort toward a goal aligned with the ideology. It is believed that a high level of ideology conviction will result in commitment, involvement, and concentration of energy [35].

Conviction of the OSS ideology is expected to energize individual effort. The OSS movement is ideologically rich in meaning. For example, many proponents of OSS argue that making the source code freely available helps increase the software's value to individual users and to society as a whole [64], while proprietary software is immoral and can harm society. According to SDT, an individual who shares the values of the OSS movement will perceive working hard on an OSS project as meaningful and purposeful, rather than just performing the task per se $[19,61]$. This meaningfulness involves the individual intrinsically caring about developing OSS and represents an investment of psychic energy. As such, the more the individual shares the 
values of OSS ideology, the higher the level of effort expended [5, 44, 51, 66]. Therefore,

Hypothesis 4a: Ideology conviction positively affects an individual's effort intensity in OSS projects.

Hypothesis 4b: Ideology conviction positively affects an individual's goal commitment in OSS projects.

Parsons defined effort as the means by which motivation is translated into accomplished work [55]. This definition suggests that effort plays a mediating role between motivation and work outcomes. According to SDT, motivation, as an intention to act, cannot lead to performance directly [19]. Instead, it is effort that translates motivation into behavior outcomes (e.g., task performance) $[12,36]$. Alternatively, if there is no effort, motivations can have no effect on behavior outcomes $[47,50]$. The mediating role of effort is empirically supported in many fields of research, such as psychology and marketing [12, $14,16]$. In particular, there is consistent theoretical and empirical support for effort's mediating role in the effect of antecedents on performance [12, 13]. Therefore, it is proposed that effort (i.e., effort intensity and goal commitment) fully mediates the relationship between motivational factors and individual performance in OSS projects.

Hypothesis 5a: Effort intensity mediates the relationships between motivations and an individual's task performance in OSS projects.

Hypothesis 5b: Goal commitment mediates the relationships between motivations and an individual's task performance in OSS projects.

To fully account for the differences among individual participants, the study also considers four control variables pertinent to the context and characteristics of OSS projects: project team size, product type, whether the participant is compensated, and the roles participants play in their projects. These variables were selected because they may have an impact on task effort expended on the project, although investigation of the effects of these variables is scant in the literature. For example, project team size, to a certain extent, manifests its success and thus may inspire participants to expend more effort. In addition, the role played by an individual in the project may affect the level of effort expended. In particular, a core developer may be more affectively involved in the project and thus expend more effort than a peripheral developer.

\section{Research Methodology}

\section{Data Collection}

To test the research model, a survey was conducted to collect data from OSS project participants. The respondents were randomly selected from discussion forums hosted by sourceforge.net and some other on-line forums, such 
as MySQL and OpenOffice. About 2,000 invitations were sent out, and the respondents were asked to fill out questionnaires posted through SurveyMonkey, an on-line survey service provider. One week later, respondents were sent a first reminder to urge their participation in the survey. A second reminder was sent one week after the first one. A total of 225 people responded to the invitations. Among returned questionnaires, 17 were incomplete and were discarded. Nonresponse bias was tested by the method suggested by Armstrong and Overton [3]. That is, the chi-squares of the responses from the first 25 percent of the respondents and the final 25 percent were compared. A significant difference would indicate the presence of nonresponse bias. The results showed that there was no nonresponse bias.

The participants were asked to describe an OSS project in which they had recently been involved and to answer the questionnaire questions based on this project. Table 2 shows the demographic data of the respondents and their participation in the OSS projects.

\section{Measures}

The measurement items in the questionnaire were adapted from existing validated and well-tested scales in the literature. The scales had been proved to have good validity and reliability. In the questionnaire, all items were measured with five-point Likert scales ranging from "strongly disagree" to "strongly agree." The choice of "not applicable" was also provided. The Appendix shows all the measurement items applied in the data collection.

The instruments for intrinsic and extrinsic motivation were adapted from Amabile et al. [2]. The instruments for ideology conviction and social identification were adapted from Becker et al. and from Allen and Meyer [1, 8]. Task intensity and goal commitment were measured by items adapted from Yeo and Neal [78]. Task performance was measured by items adapted from Tsai, Chen, and Liu [72]. Among the control variables, the direct answers were used for roles played, product types, and compensation, and the answers were grouped into discrete values for project sizes. Table 2 shows the statistics of the four control variables.

\section{Data Analysis and Results}

Partial least squares, or PLS (PLS-Graph 3.00), was utilized to assess the measurement scales and the proposed hypotheses. PLS is a multivariate technique for testing the psychometric properties of the scales for measuring a construct, and for estimating the parameters of a structural model. As a component-based structural equation modeling technique, PLS is, in essence, exploratory and focuses on explaining variance [26, 27]. Thus PLS was appropriate for the present research because the proposed model has new relationships that have not been investigated before.

There were two stages for data analysis. In Stage 1, all the instruments were assessed in a measurement model for reliability and construct validity 


\begin{tabular}{|c|c|c|}
\hline Category & $\begin{array}{c}\text { Frequency } \\
(n=204)\end{array}$ & Percent \\
\hline \multicolumn{3}{|l|}{ Gender } \\
\hline Female & 8 & 3.9 \\
\hline Male & 196 & 96.1 \\
\hline \multicolumn{3}{|l|}{ Age } \\
\hline $18-21$ & 15 & 7.6 \\
\hline $22-25$ & 34 & 16.7 \\
\hline $26-30$ & 52 & 25.5 \\
\hline $31-35$ & 32 & 15.7 \\
\hline $36-40$ & 25 & 12.3 \\
\hline $40-50$ & 30 & 14.7 \\
\hline $51+$ & 16 & 7.8 \\
\hline \multicolumn{3}{|l|}{ Education } \\
\hline High school or below & 16 & 7.8 \\
\hline Two years of college & 17 & 8.3 \\
\hline Bachelor's degree & 74 & 36.3 \\
\hline Master's degree and above & 74 & 36.3 \\
\hline Other & 23 & 11.3 \\
\hline \multicolumn{3}{|l|}{ Role in OSS project } \\
\hline User of product of this project (use code as is) & 72 & 35.3 \\
\hline Core developer of project & 79 & 38.7 \\
\hline Peripheral developer (bug reporting and fixing) & 25 & 12.3 \\
\hline Translator & 6 & 2.9 \\
\hline User experience/User interface expert & 7 & 3.4 \\
\hline Other & 14 & 6.9 \\
\hline \multicolumn{3}{|l|}{ Software product type } \\
\hline Operating system (e.g., Linux) & 16 & 7.8 \\
\hline Database management system (e.g., MySQL) & 12 & 5.9 \\
\hline Development platform (e.g., Eclipse) & 28 & 13.7 \\
\hline Server-side application (e.g., Apache) & 29 & 14.2 \\
\hline Office application (e.g., OpenOffice) & 17 & 8.3 \\
\hline Domain-specific application (e.g., education, entertainment) & 74 & 36.3 \\
\hline Other & 28 & 13.7 \\
\hline \multicolumn{3}{|l|}{ Compensation from OSS projects } \\
\hline Yes, as salary & 28 & 13.7 \\
\hline Yes, as bonus & 2 & 1.0 \\
\hline Yes, as side income & 10 & 4.9 \\
\hline No & 162 & 79.4 \\
\hline \multicolumn{3}{|l|}{ Project size (number of people in immediate group) } \\
\hline $0-10$ & 155 & 76.0 \\
\hline $11-30$ & 19 & 9.3 \\
\hline $31-99$ & 3 & 1.5 \\
\hline $100+$ & 1 & 0.5 \\
\hline
\end{tabular}

Table 2. Sample Demography and Participation in OSS Projects.

using confirmatory factor analysis (CFA). In Stage 2, the proposed models and hypotheses were tested, with the individual path coefficients and variance explained in the dependent variables examined in the structural model. In both stages, all measured items were modeled as reflective indicators of their corresponding latent constructs. 


\begin{tabular}{llll} 
Constructs & Item & Mean & $\begin{array}{c}\text { Standard } \\
\text { deviation }\end{array}$ \\
\hline \multirow{2}{*}{ Task performance } & TASK_1 & 2.89 & 1.3 \\
& TASK_2 & 3.09 & 1.14 \\
Effort intensity & TASK_3 & 2.84 & 1.16 \\
& EFF_1 & 4.06 & 0.89 \\
Goal commitment & EFF_2 & 3.72 & 1.11 \\
& EFF_3 & 3.86 & 0.97 \\
Ideology conviction & GOAL_1 & 3.23 & 1.28 \\
& GOAL_2 & 3.64 & 1.31 \\
Social identification & GOAL_3 & 3.67 & 1.04 \\
& IDEO_1 & 3.71 & 0.99 \\
& IDEO_2 & 3.45 & 0.97 \\
& SOC_ID_1 & 3.9 & 0.95 \\
& SOC_ID_2 & 3.62 & 0.95 \\
Extrinsic motivation & SOC_ID_3 & 4.03 & 0.9 \\
& SOC_ID_4 & 4.2 & 0.9 \\
Intrinsic motivation & SOC_ID_5 & 3.74 & 1.14 \\
& SOC_ID_6 & 3.63 & 1.15 \\
& EXT_M_1 & 2.54 & 1.41 \\
& EXT_M_2 & 2.8 & 1.29 \\
& EXT_M_3 & 3.57 & 1.22 \\
& INT_M_1 & 3.96 & 0.97 \\
& INT_M_2 & 4.22 & 0.88 \\
& INT_M_3 & 4.14 & 0.96
\end{tabular}

Table 3. Descriptive Statistics of Variables.

\section{Measurement Model}

Table 3 provides the descriptive statistics of the variables used in the survey. Convergent validity and discriminant validity were used to examine the measurement scales [28]. Convergent validity was assessed by (1) reliability of items, (2) composite reliability of constructs, and (3) average variance extracted (AVE) [23, 76]. Reliability of items was assessed by each item's loading on its corresponding construct. A rule of thumb suggests that the item loading should exceed 0.70 . As can be seen in Table 4, the loadings (in boldface) for all items exceeded 0.70 .

Composite reliability is recommended to be 0.70 or higher. Table 5 shows that the composite reliabilities (CR) of all the constructs exceeded 0.70, with the lowest value being 0.80 for ideology conviction. AVE measures the amount of variance that a construct captures from its indicators relative to the amount due to measurement error [15]. It is recommended that it should exceed 0.50. Table 5 shows that the AVEs of all constructs exceeded 0.50, with the lowest value at 0.62 . Hence, all three conditions for convergent validity were met.

Discriminant validity between constructs was assessed using Fornell and Larcker's recommendation that the square root of the AVE for each construct should exceed the correlations between this construct and all the other constructs $[15,23]$. In Table 5 , the boldface numbers on the diagonals are the square roots of the AVEs. Off-diagonal elements are the correlations among constructs. 


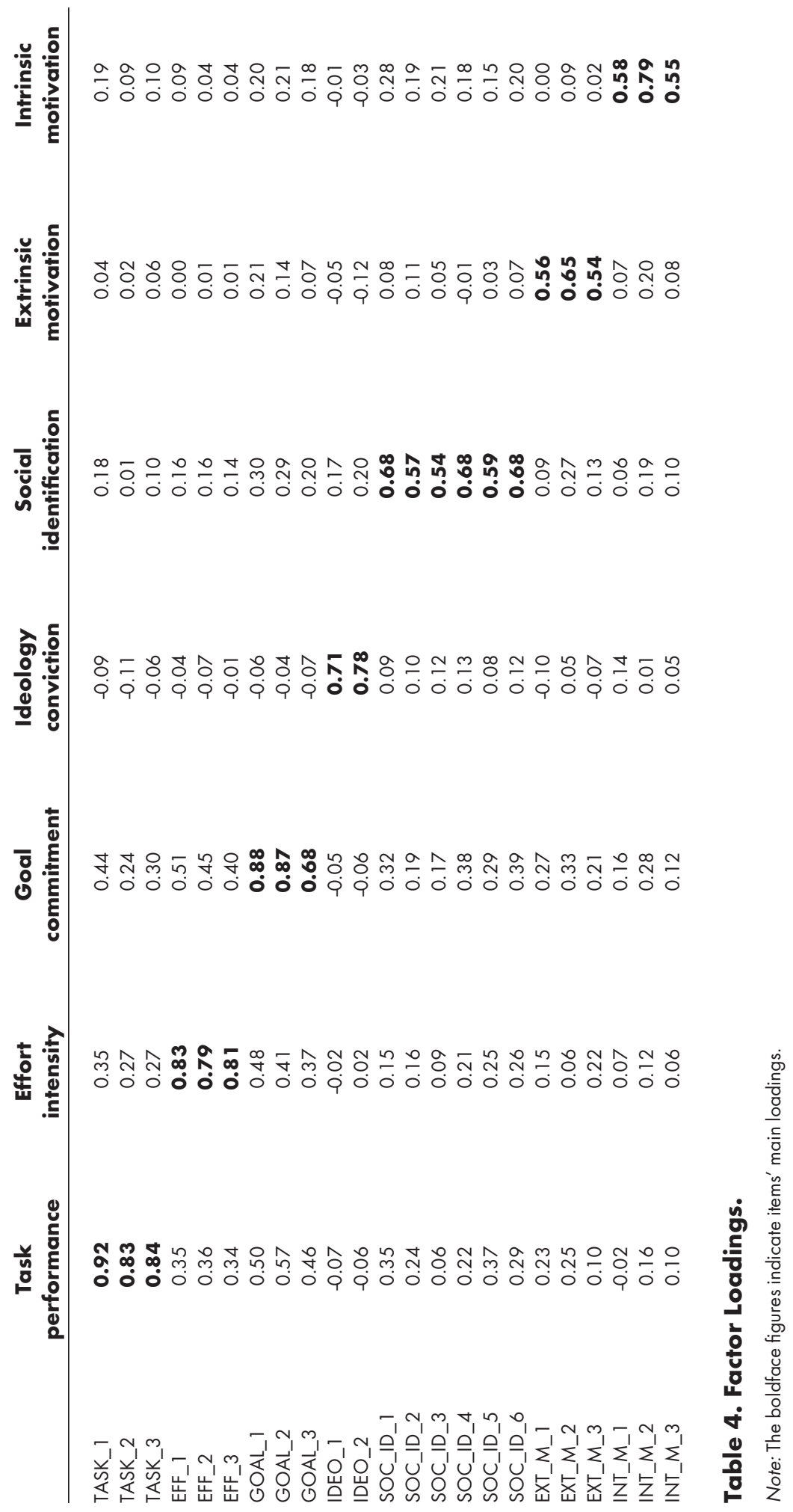




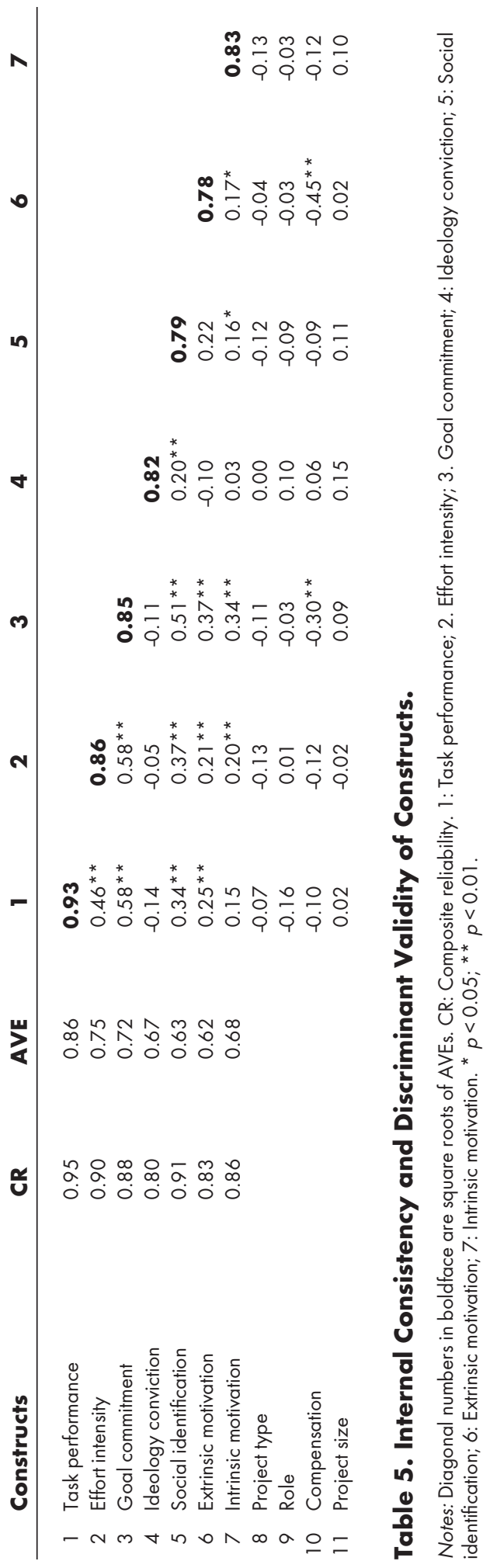


All diagonal numbers are much greater than the corresponding off-diagonal ones, indicating satisfactory discriminant validity of all the constructs.

Another criterion for discriminant validity is that no measurement item should load more highly on any construct other than the construct it intends to measure. Based on the guideline from Gefen, Straub, and Boudreau, the difference between the loading on the supposed construct and the loading on other constructs should be more than 0.10 [27]. An examination of loadings and cross-factor loadings showed that all items satisfied this guideline (see Table 4).

\section{Common Method Bias}

Since self-reported data were collected at one time point in one context for all variables involved, there were possible sources for common method bias, including social desirability [57]. Before the research model and the hypotheses were tested, an analysis with PLS was conducted to test whether common method bias would be a concern, following the method used by Liang et al. [43]. Specifically, a common method factor was introduced in the PLS model whose indicators included the indicators of all the principal constructs. Each indicator's variances were then calculated as substantively explained by the principal constructs and by the method factor. As shown in Table 6, the average of variances substantively explained by the principle constructs is 0.709 , while the average of variance explained by the method-based factor was 0.010 . The ratio of substantive variance to method variance was about 70:1, indicating a very small magnitude of method variance. In addition, although some of the method loadings were significant, the ratio of the variances explained by the principal constructs and the variances explained by the method factor was $0.709 / 0.010=70.9$, making the variances explained by the method factor insignificant. Thus, it is contended that common method bias is not a serious concern for this study.

\section{Structural Model}

The four control variables - project size, product type, compensation, and participant's major role in the OSS project-were considered during the analysis of the structural model. The result of the structural model is shown in Figure 2. Among the four control variables, only compensation had a negative effect on goal commitment. In general, the research model was largely supported, with some exceptions on certain hypotheses. Specifically, the positive effects of intrinsic motivation on effort intensity (H1a) and on goal commitment (H1b) were supported. The positive effect of extrinsic motivation on effort intensity (H2a) was not supported; its effect on goal commitment (H2b) was supported. $\mathrm{H} 3 \mathrm{a}$ and $\mathrm{H} 3 \mathrm{~b}$ on the positive relationship between social identification and effort intensity, and between social identification and goal commitment, respectively, were supported. For $\mathrm{H} 4 \mathrm{a}$ and $\mathrm{H} 4 \mathrm{~b}$, the empirical data showed that ideology conviction had a negative, rather than positive, effect. In particular, 


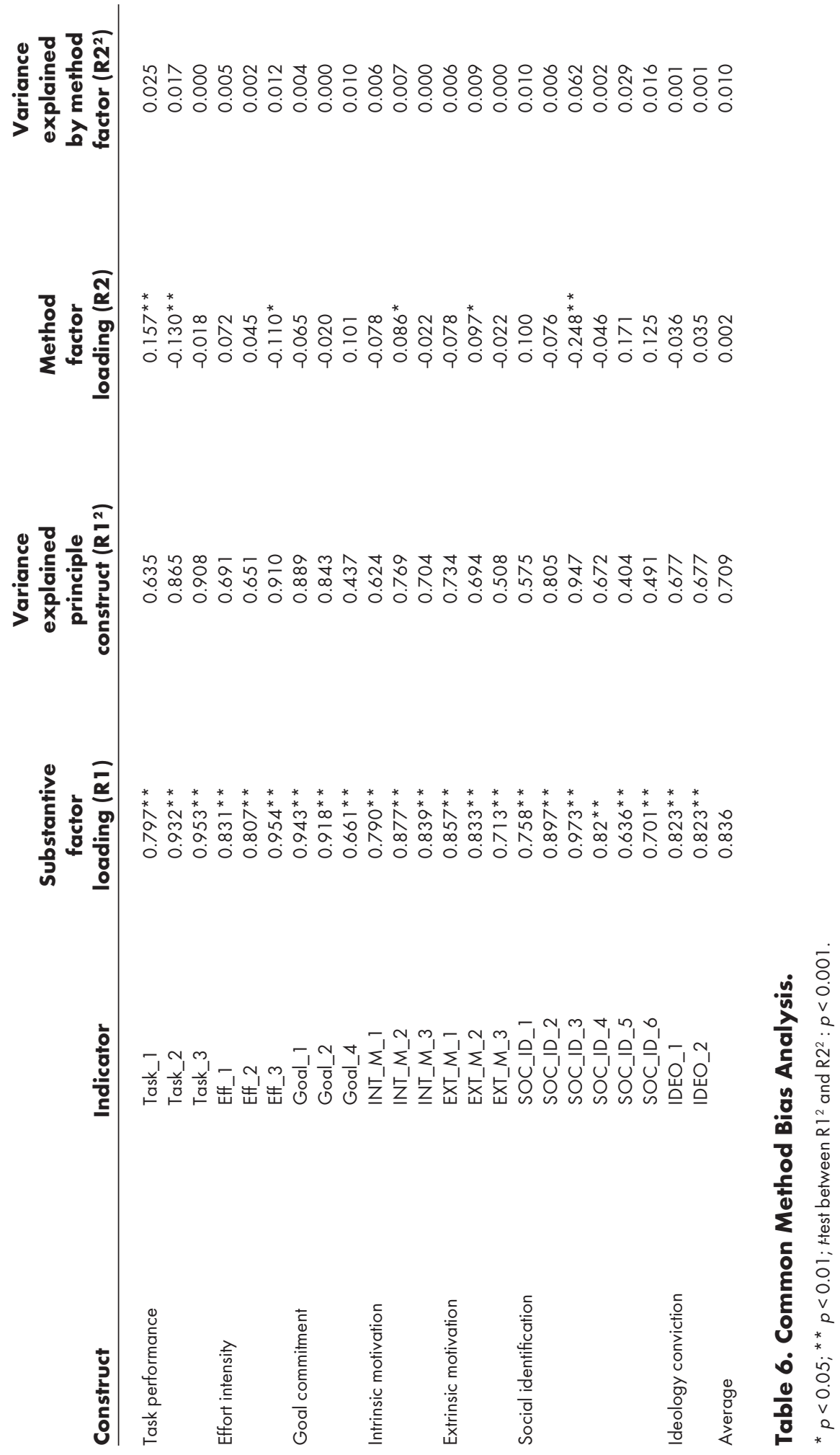




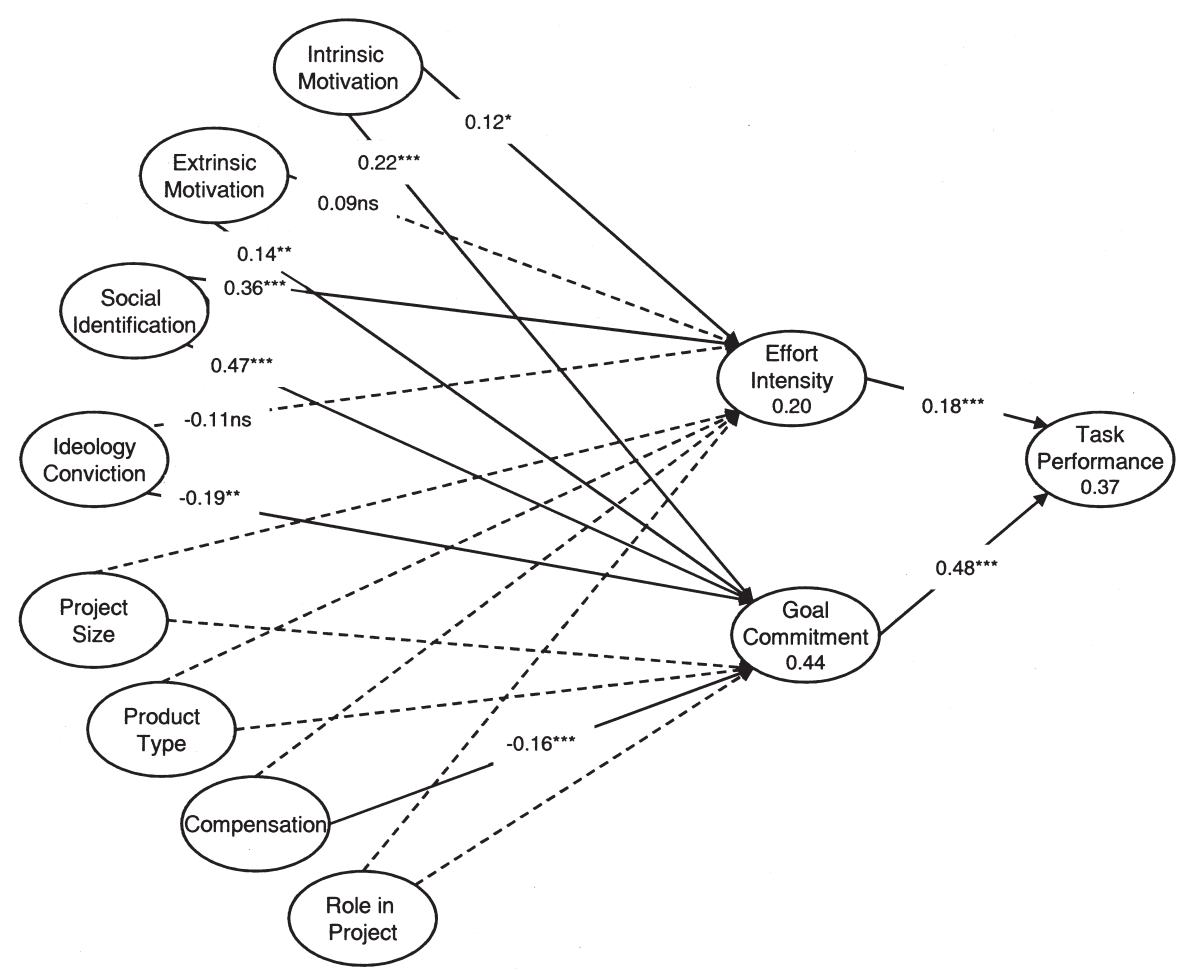

Figure 2. Structural Model with Control Variables

Notes: ns $=$ nonsignificant. ${ }^{*} p<0.10 ;{ }^{*} p<0.05 ;{ }^{* *} p<0.01$.

ideology conviction had a significant, negative effect on goal commitment and a nonsignificant, negative effect on effort intensity. Hypotheses $\mathrm{H} 5 \mathrm{a}$ and $\mathrm{H} 5 \mathrm{~b}$, which proposed positive relationships between task performance and effort intensity, and between task performance and goal commitment, respectively, were supported. Overall, the model explained 37 percent of the variances in task performance, 44 percent in goal commitment, and 20 percent in effort intensity.

Additional analyses were conducted to test the mediating effects of effort intensity and goal commitment. Following the three-step procedure suggested by Baron and Kenny [7], it was found that, except for intrinsic motivation, the other three independent variables all had direct significant effects on task performance, with a coefficient of 0.15 for extrinsic motivation, 0.35 for social identification, and -0.20 for ideology conviction, as shown in Figure 3. When effort intensity and goal commitment are included as mediators in the model, these three variables no longer had significant direct effects on task performance (see Figure 4). This means that effort intensity and goal commitment fully mediate the effects of extrinsic motivation, social identification, and ideology conviction on task performance. Additional examinations showed the different mediating roles between effort intensity and goal commitment. Especially, goal commitment alone fully mediated the effects of extrinsic 


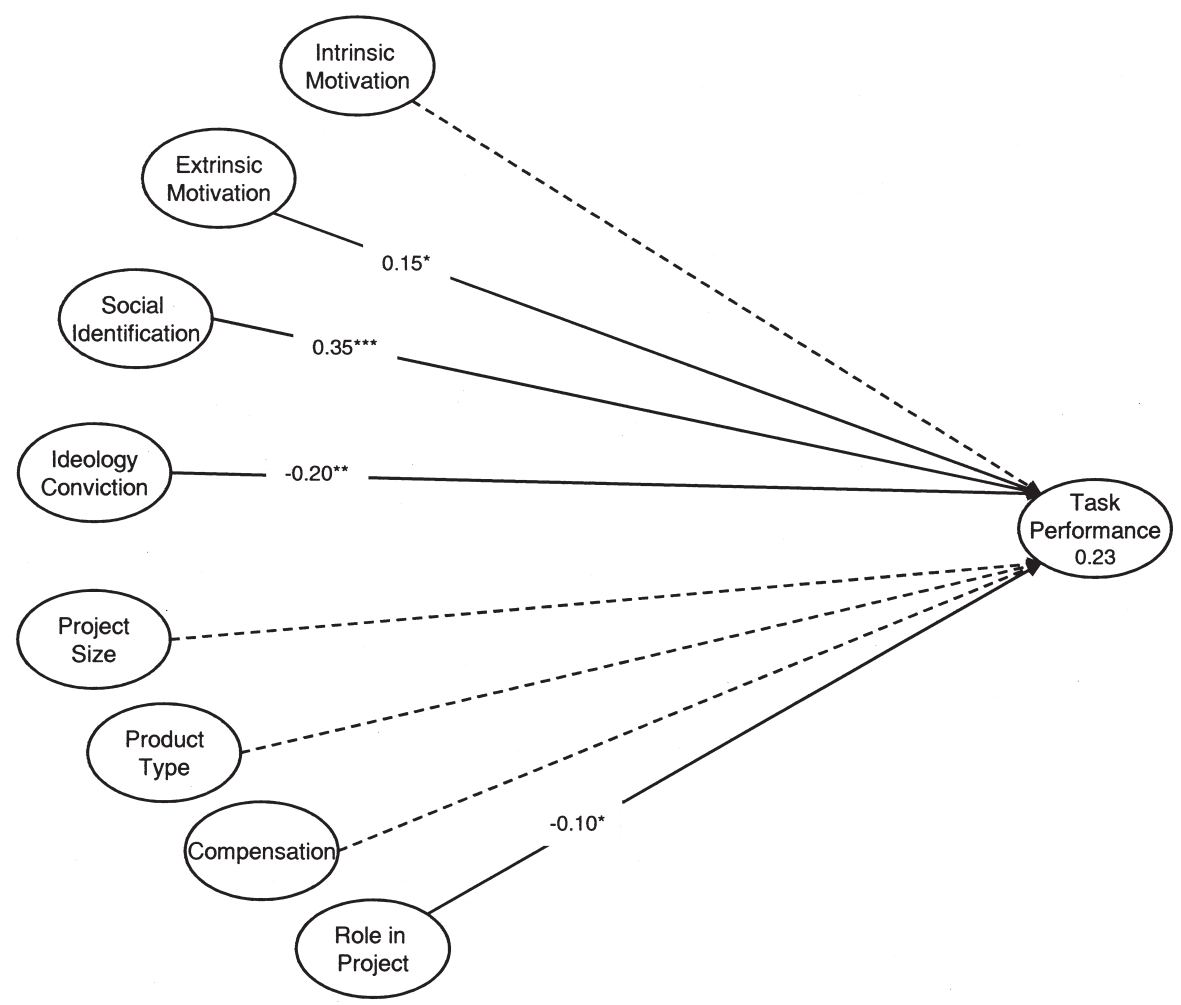

Figure 3. Direct Effects Without Presence of Mediators

Notes: ns $=$ nonsignificant. ${ }^{*} p<0.10 ;{ }^{* *} p<0.05 ;{ }^{* * *} p<0.01$.

motivation and ideology conviction on task performance; goal commitment and effort intensity together fully mediated social identification's effect on task performance.

\section{Discussion and Conclusion}

This study revealed some interesting and important new findings. First, it indicated that among the four types of motivational factors, social identification with the OSS project group had the largest effect on participants' effort intensity and goal commitment. Given that most research on OSS participants' motivations has been focused on the effects of personal motivations, namely intrinsic and extrinsic motivation, this finding sheds new light on our understanding of the motivators of OSS participation. Such a finding calls for future investigations to further examine the antecedents and effects of social identification.

Second, the finding on extrinsic motivation's different effects on goal commitment and effort intensity is also new. Prior studies examined whether extrinsic motivation motivates individuals to contribute to OSS communities 


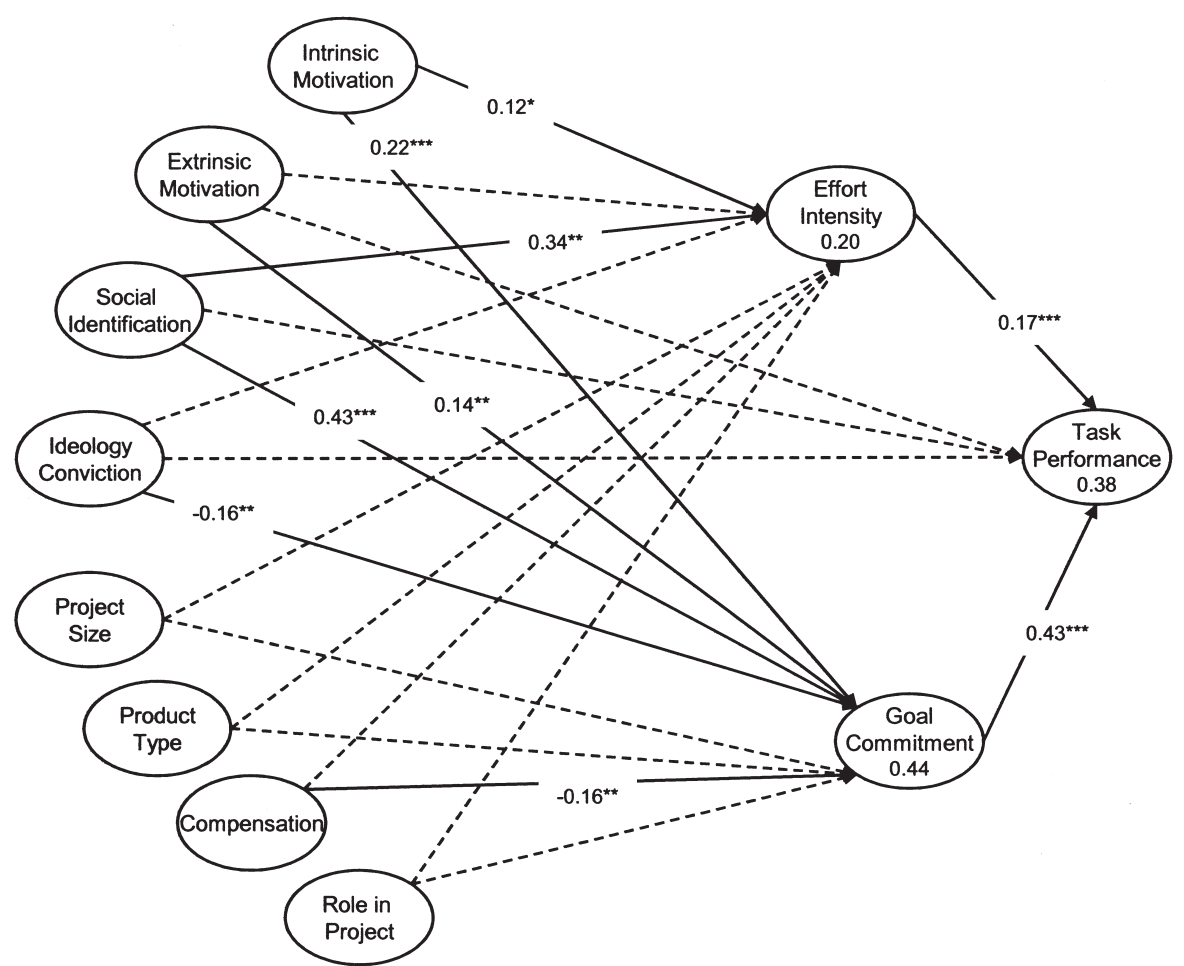

Figure 4. Direct Effects with Presence of Mediators

Notes: ns $=$ nonsignificant. ${ }^{*} p<0.10 ;{ }^{*} p<0.05 ;{ }^{*}{ }^{*} p<0.01$.

and neglected the influencing process of this motivator. The result shows that extrinsic motivation can keep individuals engaged (i.e., committed to the task) but does not lead them to exert themselves fully on tasks; thus, they do not exhibit effort intensity. One possible explanation for the nonsignificant effect of extrinsic motivation on effort intensity is that OSS participants are mostly volunteers (see Table 2 on compensation: almost 80 percent of participants do not receive any compensation from OSS projects). Either they might not have given OSS participation top priority, or they were unable to spend as much time on OSS projects as they desired.

Third, ideological conviction was found to have negative effects on task effort. This finding was surprising initially, as it was contrary to what is suggested in the literature (e.g., [66]) and the hypotheses. After examining the justifications for the hypotheses, the measurement items of ideology and task effort (i.e., effort intensity and goal commitment), and the characteristics of the participants and their reported projects, it would appear that such different effects are possible. In the hypotheses and the measurement items, ideology is about the values of the OSS community or the OSS movement in general. On the other hand, task effort, including both effort intensity and goal commitment, is about the particular project the participants reported. When two hypothetically related constructs are measured toward different objects and 
thus with different specificity, their causal relationship may be dependent on other factors or on the situation. The participants' projects were of various sizes, which is different from past studies that considered only large projects, such as Linux and Apache (e.g., [60, 63]). In large projects, it is easier for participants to identify the OSS values and then share or be inclined to them. In small projects, participants are more likely driven by their personal demands for the software. This may make it less easy for the participants to be aligned with the ideology of the OSS community. In addition, the participants in the study included many types of people involved in OSS projects, such as developers, users, and translators, among others, while past studies focused on developers only. Even if users strongly identify with the OSS community ideology, they may not expend as much effort on OSS participation as developers do. In summary, the specific situations as indicated by the study's participants and their projects do not warrant the hypothesized relationship between ideology and task effort. The negative effects state that participants with high ideology have low task effort (e.g., users, as mentioned above), and participants with low ideology have high task effort (e.g., some of the smallproject developers). This indicates that it may not be appropriate to expect that high OSS ideology leads to high OSS task effort. The relationship may be dependent on other factors or on the situation. Future researchers are urged to investigate the effects of ideology conviction on the behavior of different types of participants in OSS projects of different sizes.

Finally, and probably most important, this research shows that task effort mediates the relationships between motivators and OSS participants' behavior outcomes. Specifically, the study found that effort intensity and goal commitment, the two aspects of task effort, were related differently to the motivators and behavior outcomes. For example, goal commitment alone fully mediated the effects of extrinsic motivation and ideology conviction on task performance. In contrast, effort intensity worked together with goal commitment to influence the social identification-performance relationship. This finding enriches our understanding of the influencing process of motivators in affecting individuals' contributions to OSS projects.

It is important to evaluate the study's results and contributions in light of its limitations. First, there are other salient factors that can affect an individual's performance in and satisfaction with an OSS project, such as leadership style and individual competence. While an effort was made to provide an integrated model, the study did not provide an exhaustive list of antecedents of individual task performance. Future research should enrich the current theoretical model by examining the effects of other factors and assessing the influence of possible moderators and other mediators. Second, data were collected from a single source during one period of time. All the major constructs were measured by respondents' perceptions, which are subjective. Future research should use some objective measures from multiple sources. Ideally, future research should also collect data at multiple points in time. A longitudinal study might enrich research findings by offering additional information on the causal relationships between independent and dependent variables. Third, in this first study to examine the effects of motivators on individuals' participation outcomes in OSS communities, data were collected from English-speaking OSS participants. 
OSS development, as a global phenomenon, involves individuals speaking various languages and with diverse national cultures. Future research should be conducted to verify the applicability of the present research results to participants speaking different languages and of different cultures.

The study makes several major theoretical contributions. First, it unveils how motivational factors are translated into achieved outcomes through task effort. Examining the mediating role played by task effort extends our understanding of the underlying mechanism of motivational factors in OSS communities and may help explain the inconsistent and controversial empirical research findings on the importance of different motivational factors (e.g., [60, 63]). Second, this was the first study to incorporate a complete set of motivations in a single model to examine how they affect task performance in OSS projects. The research findings indicate that different types of motivations have different effects on task effort and thus affect task performance differently. This integrated model provides a better picture of what drives individual engagement in and contribution to OSS projects, which are critical for the viability and sustainability of OSS communities. More important, the study underscores the importance and necessity to treat motivation as a multidimensional concept; thus, examining motivation as a unitary construct can be misleading. Third, despite the popular belief that ideology conviction influences OSS behavior, the study indicates that the actual effects of ideology conviction on task effort and outcome may depend on other factors or situations. Previous studies focused on developers in large OSS projects. Their findings need to be cautiously applied in research studies of OSS projects of other sizes.

The study also has practical implications for the management of OSS projects. In particular, the four types of motivations have significant impacts on OSS task effort and outcomes. OSS project leaders and other stakeholders should find ways to maximize such motivations (with caution on ideology conviction). For social identification, which was found to have the largest impact on effort intensity and goal commitment, OSS project leaders and stakeholders may want either to be selective in recruiting project members or to find ways to increase members' social identification with the project. A high cohesion in social identification within a project group will drive participants to expend effort on the project, which, in turn, will lead to high task performance. Extrinsic motivation might be enhanced so that participants can find more reasons for being involved in OSS projects. Although it is hard for outsiders to control and manipulate intrinsic motivation, OSS project leaders and stakeholders may find ways to identify and match individuals' intrinsic motivations with tasks assigned and to provide facilitations if necessary. For example, assigning cognitively challenging tasks to participants can satisfy their intrinsic motivation, which in turn affects task effort. Due to ideology's different effects on task effort in previous studies, it is not yet possible to make practical suggestions on this factor; researchers and practitioners are encouraged to investigate further on this important concept and its consequences.

Knowing that effort intensity and goal commitment mediate the relationship between motivation and performance, practitioners should realize that having various motivations will not influence task performance directly. OSS 
project leaders can influence task performance by directly affecting task effort expended. Specifically, project leaders can call upon participants to work hard on the chosen task and encourage and support participants when they face difficulties and barriers. Indeed, influencing goal commitment directly may be the most effective path to high task performance, given its significant effect on task performance.

Finally, OSS practitioners and managers should realize that task effort is just one possible contributor to task performance. This research found that a good portion of the variance in task performance can be explained by the model. Yet a large portion of the variance is unexplained. It is beyond the scope of this paper to discuss other influencing factors. Additional research in this area is needed to identify and investigate the other salient factors that contribute to OSS task performance.

\section{REFERENCES}

1. Allen, N.J., and Meyer, J.P. Affective, continuance, and normative commitment to the organization: An examination of construct validity. Journal of Vocational Behavior, 49, 3 (1996), 252-276.

2. Amabile, T.M.; Hill, K.G.; Hennessey, B.A.; and Tighe, E.M. The work preference inventory: Assessing intrinsic and extrinsic motivational orientations. Journal of Personality and Social Psychology, 66, 5 (1994), 950-967.

3. Armstrong, J.S., and Overton, T.S. Estimating nonresponse bias in mail surveys. Journal of Marketing Research, 14, 3 (1977), 396-402.

4. Atkinson, J.W. An Introduction to Motivation. Princeton, NJ: Van Nostrand, 1964.

5. Bagozzi, R.P., and Dholakia, U.M. Open source software user communities: A study of participation in Linux user groups. Management Science, 52, 7 (2006), 1099-1115.

6. Bagozzi, R.P., and Lee, K.H. Multiple routes for social influence: The role of compliance, internalization, and social identity. Social Psychology Quarterly, 65, 3 (2002), 226-247.

7. Baron, R.M., and Kenny, D.A. The moderator-mediator distinction in social psychology research: Conceptual, strategic and statistical considerations. Journal of Personality and Social Psychology, 51, 6 (1986), 1173-1183.

8. Becker, T.E.; Billings, R.S.; Eveleth, D.M.; and Gilbert, N.L. Foci and bases of employee commitment: Implications for job performance. Academy of Management Journal, 39, 2 (1996), 464-482.

9. Benkler, Y. The Wealth of Networks: How Social Production Transforms Markets and Freedom. New Haven: Yale University Press, 2006.

10. Bergami, M., and Bagozzi, R.P. Self-categorization, affective commitment and group self-esteem as distinct aspects of social identity in the organization. British Journal of Social Psychology, 39, 4 (2000), 555-577.

11. Bonaccorsi, A.; Giannangeli, S.; and Rossi, C. Entry strategies under competing standards: Hybrid business models in the open source software industry. Management Science, 52, 7 (2006), 1085-1098. 
12. Brown, S.P., and Leigh, T.W. A new look at psychological climate and its relationship to job involvement, effort, and performance. Journal of Applied Psychology, 81, 4 (1996), 358-368.

13. Brown, S.P., and Peterson, R.A. Antecedents and consequences of salesperson job satisfaction: Meta-analysis and assessment of causal effects. Journal of Marketing Research, 30, 1 (1993), 63-77.

14. Brown, S.P., and Peterson, R.A. The effect of effort on sales performance and job satisfaction. Journal of Marketing, 58, 2 (1994), 70-80.

15. Chin, W.W. The partial least squares approach to structural equation modeling. In G.A. Marcoulides (ed.), Modern Methods for Business Research. Mahwah, NJ: Lawrence Erlbaum, 1998, pp. 295-336.

16. Christen, M.; Iyer, G.; and Soberman, D. Job satisfaction, job performance, and effort: A reexamination using agency theory. Journal of Marketing, 70, 1 (2006), 137-150.

17. Deci, E.L. Intrinsic Motivation. New York: Plenum Press, 1975.

18. Deci, E.L., and Ryan, R.M. Intrinsic Motivation and Self-Determination in Human Behavior. New York: Plenum Press, 1985.

19. Deci, E.L., and Ryan, R.M. The "what" and "why" of goal pursuits: Human needs and the self-determination of behavior. Psychology Inquiry, 11, 4 (2000), 227-268.

20. Deci, E.L.; Koestner, R.; and Ryan, R.M. A meta-analytic review of experiments examining the effects of extrinsic rewards on intrinsic motivation. Psychology Bulletin, 125, 6 (1999), 627-668.

21. Ellemers, N.; De Gilder, D.; and Haslam, S.A. Motivating individuals and groups at work: A social identity perspective on leadership and group performance. Academy of Management Review, 29, 3 (2004), 459-478.

22. Ellemers, N.; Kortekaas, P.; and Ouwerkerk, J.W. Self-categorisation, commitment to the group and group self-esteem as related but distinct aspects of social identity. European Journal of Social Psychology, 29, 2-3 (1999), 371-389.

23. Fornell, C., and Larcker, D.F. Structural equation models with unobservable variables and measurement errors. Journal of Marketing Research, 18, 2 (1981), 39-50.

24. Franke, N., and von Hippel, E. Satisfying heterogeneous user needs via innovation toolkits: The case of Apache security software. Research Policy, 32, 7 (2003), 1199-1215.

25. Gagne, M., and Deci, E.L. Self-determination theory and work motivation. Journal of Organizational Behavior, 26, 4 (2005), 331-362.

26. Gefen, D. Customer loyalty in e-commerce. Journal of the Association for Information Systems, 3, 1 (2002), 27-51.

27. Gefen, D.; Straub, D.; and Boudreau, M. Structural equation modeling and regression: Guidelines for research practice. Communications of the Association for Information Systems, 4, 7 (2000), 1-77.

28. Hair, J.F.; Anderson, R.E.; Tatham, R.L.; and Black, W.C. Multivariate Data Analysis. Englewood Cliffs, NJ: Prentice Hall, 1998.

29. Hann, I.H.; Roberts, J.A.; and Slaughter, S.A. Delayed returns to open source participation: An empirical analysis of the Apache HTTP server 
project. Paper presented at the Open Source: Economics, Law, and Policy conference, Toulouse, France, 2002.

30. Hars, A., and Ou, S.S. Working for free? Motivations for participating in open source projects. International Journal of Electronic Commerce, 6, 3 (2002), 25-39.

31. Hertel, G.; Niedner, S.; and Herrmann, S. Motivation of software developers in open source projects: An Internet-based survey of contributors to the Linux kernel. Research Policy, 32, 7 (2003), 1159-1177.

32. Hollenbeck, J.R.; Williams, C.L.; and Klein, H.J. An empirical examination of the antecedents of commitment to difficult goals. Journal of Applied Psychology, 74, 1 (1989), 18-23.

33. Kahn, W.A. Psychological conditions of personal engagement and disengagement at work. Academy of Manage Journal, 33, 4 (1990), 692-724.

34. Kanfer, R. Motivation theory and industrial and organizational psychology. In M.D. Dunnette and L.M. Hough (eds.), Handbook of Industrial and Organizational Psychology. Palo Alto, CA: Consulting Psychologists Press, 1992, pp. 75-170.

35. Kanter, R.M. Commitment and social organization: A study of commitment mechanisms in utopian communities. American Sociological Review, 33, 4 (1968), 499-517.

36. Klein, H.J.; Wesson, M.J.; Hollenbeck, J.R.; and Alge, B.J. Goal commitment and the goal-setting process: Conceptual clarification and empirical synthesis. Journal of Applied Psychology, 84, 6 (1999), 885-896.

37. Lakhani, K.R., and von Hippel, E. How open source software works: "Free" user-to-user assistance. Research Policy, 32, 6 (2003), 923-943.

38. Lakhani, K.R., and Wolf, R.G. Why hackers do what they do: Understanding motivation and effort in free/open source software projects. In J. Feller, B. Fitzgerald, S. Hissam, and K.R. Lakhani (eds.), Perspectives on Free and Open Source Software. Cambridge, MA: MIT Press, 2005, pp. 3-22. 39. Lakhani, K.R.; Wolf, R.G.; and Bates, J. The Boston Consulting Group Hacker Survey, Release 0.3. 2002, Boston Consulting Group, http:/ / flosscom.net $/$ index.php?option=com_docman\&task=doc_view\&gid $=45$, accessed November 6, 2008.

40. Lee, G.K., and Cole, R.E. From a firm-based to a community-based model of knowledge creation: The case of the Linux kernel development. Organization Science, 14, 6 (2003), 633-649.

41. Lerner, J., and Tirole, J. Some simple economics of open source. Journal of Industrial Economics, 50, 2 (2002), 197-234.

42. Lewin, K. The Conceptual Representation and the Measurement of Psychological Force. Durham, NC: Duke University Press, 1938.

43. Liang, H.; Saraf, N.; Hu, Q.; and Xue, Y. Assimilation of enterprise systems: The effect of institutional pressures and the mediating role of top management. MIS Quarterly, 31, 1 (2007), 59-87.

44. Ljungberg, J. Open source movements as a model for organising. European Journal of Information Systems, 9, 4 (2000), 208-216.

45. Locke, E.A. Toward a theory of task motivation and incentives. Organizational Behavior and Human Performance, 3, 2 (1968), 157-189. 
46. Locke, E.A., and Latham, G.P. The determinants of goal acceptance and commitment. Academy of Manage Review, 13, 1 (1988), 23-39.

47. Locke, E.A., and Latham, G.P. A Theory of Goal Setting and Task Performance. Englewood Cliffs, NJ: Prentice-Hall, 1990.

48. Locke, E.A., and Latham, G.P. What should we do about motivation theory? Six recommendations for the twenty-first century. Academy of Management Review, 29, 3 (2004), 388-403.

49. Locke, E.A., and Shaw, K.N. Atkinson's inverse-U curve and the missing cognitive variables. Psychological Reports, 55, 2 (1984), 403-412.

50. Locke, E.A.; Shaw, K.N.; Saari, L.M.; and Latham, G.P. Goal setting and task performance: 1969-1980. Psychology Bulletin, 90, 1 (1981), 125-152.

51. Markus, M.L.; Manville, B.; and Agres, C.E. What makes a virtual organization work? Sloan Management Review, 42, 1 (2000), 13-26.

52. Mento, A.J.; Cartledge, N.D.; and Locke, E.A. Maryland vs. Michigan vs. Minnesota: Another look at the relationship of expectancy and goal difficulty to task performance. Organizational Behavior and Human Performance, 25, 3 (1980), 419-440.

53. Meyer, J.P.; Becker, T.E.; and Vandenberghe, C. Employee commitment and motivation: A conceptual analysis and integrative model. Journal of Applied Psychology, 89, 6, (2004), 991-1007.

54. Mitchell, T.R., and Daniels, D. Motivation. In W.C. Borman, D.R. Ilgen, R.J. Klimoski, and I.B. Weiner (eds.), Handbook of Psychology, Industrial and Organizational Psychology, vol. 12. New York: Wiley, 2003, pp. 225-254.

55. Parsons, T. The Structure of Social Action. New York: Free Press, 1968.

56. Pinder, C.C. Work Motivation in Organizational Behavior. Upper Saddle River, NJ: Prentice Hall, 1998.

57. Podsakoff, P.; MacKenzie, S.; Lee, J.; and Podsakoff, N. Common method biases in behavioral research: A critical review of the literature and recommended remedies. Journal of Applied Psychology, 88, 5 (2003), 879-903.

58. Porter, L.W., and Lawler, E.E. Managerial Attitudes and Performance. Homewood, IL: Richard D. Irwin, 1968.

59. Raymond, E.S. The Cathedral and the Bazaar: Musings on Linux and Open Source by an Accidental Revolutionary. Sebastopol, CA: O'Reilly \& Associates, 1999.

60. Roberts, J.A.; Hann, I.H.; and Slaughter, S.A. Understanding the motivations, participation, and performance of open source software developers: A longitudinal study of the Apache projects. Management Science, 52, 7 (2006), 984-999.

61. Ryan, R.M., and Deci, E.L. Self-determination theory and the facilitation of intrinsic motivation, social development, and well-being. American Psychologist, 55, 1 (2000), 68-78.

62. Salancik, G.R. Commitment and the control of organizational behavior and belief. In B. Staw and G.R. Salancik (eds.), New Directions in Organization Behavior. Chicago: St. Clair, 1977, pp. 1-54.

63. Shah, S.K. Motivation, governance, and the viability of hybrid forms in open source software development. Management Science, 52, 7 (2006), 1000-1014. 
64. Stallman, R. Why software should be free, www.gnu.org/philosophy/ shouldbefree.html, accessed November 5, 2008.

65. Steers, R.M.; Mowday, R.T.; and Shapiro, D.L. Introduction to special topic forum: The future of work motivation theory. Academy of Management Review, 29, 3 (2004), 379-387.

66. Stewart, K.J., and Gosain, S. The impact of ideology on effectiveness in open source software development teams. MIS Quarterly, 30, 2 (2006), 291-314.

67. Stewart, K.J.; Ammeter, A.P.; and Maruping, L.M. Impacts of license choice and organizational sponsorship on user interest and development activity in open source software projects. Inform Systems Research, 17, 2 (2006), 126-144.

68. Tajfel, H. Differentiation Between Social Groups: Studies in the Social Psychology of Intergroup Relations. London: Academic Press, 1978.

69. Tajfel, H. Social identity and intergroup behavior. Social Science Information, 13, 2 (1974), 65-93.

70. Tolman, E.C. Principles of purposive behavior. In S. Koch (ed.), Psychology: A Study of a Science, vol. 2. New York: McGraw-Hill, 1959, pp. 92-157. 71. Trice, H.M., and Beyer, J.M. The Cultures of Work Organizations. Englewood Cliffs, NJ: Prentice Hall, 1993.

72. Tsai, W.; Chen, C.; and Liu, H. An integrative model linking employee positive moods and task performance. Journal of Applied Psychology, 92, 6 (2007), 1570-1583.

73. Von Hippel, E., and von Krogh, G. Open source software and the "private-collective" innovation model: Issues for organization science. Organization Science, 14, 2 (2003), 209-223.

74. Von Krogh, G., and von Hippel, E. The promise of research on open source software. Management Science, 52, 7 (2006), 975-983.

75.Vroom, V.H. Work and Motivation. New York: Wiley, 1964.

76. Werts, C.E.; Linn, R.L.; and Joreskog, K.G. Intraclass reliability estimates: Testing structural assumptions. Educational and Psychological Measurement, 34, 1 (1974), 25-33.

77. Winters, D.C. Personality: Analysis and Interpretation of Lives. New York: McGraw-Hill, 1996.

78. Yeo, G.B., and Neal, A. A multilevel analysis of effort, practice, and performance: Effects of ability, conscientiousness, and goal orientation. Journal of Applied Psychology, 89, 2 (2004), 231-247.

79. Yulk, G.A., and Latham, G.P. Interrelationships among employee participation, individual differences, goal difficulty, goal acceptance, goal instrumentality and performance. Personnel Psychology, 31, 2 (1978), 305-323.

80. Zeitlyn, D. Gift economies in the development of open source software: Anthropological reflections. Research Policy, 32, 7 (2003), 1287-1291. 


\section{Appendix: Measurement I tems}

\section{Intrinsic Motivation (adapted from [2])}

1. What matters to me the most in participating in this project is to tackle problems that are completely new to me.

2. What matters to me the most in participating in this project is to try to solve complex problems.

3. What matters to me the most in participating in this project is to enjoy fixing difficult problems.

\section{Extrinsic Motivation (adapted from [2])}

1. I am strongly motivated by the money I can earn when participating in this project.

2. I am keenly aware of the possible career promotion when participating in this project.

3. Participating in this OSS project is useful for my job.

\section{Ideology Conviction (adapted from [8])}

1. If the values of the OSS community were different, I would not be as attached to it.

2. Since I joined the OSS community, my personal values and those of the community have become more similar.

\section{Social Identity (adapted from [10])}

1. I feel a sense of belonging toward this project group.

2. I have a feeling of togetherness or closeness in this project group.

3. I have a strong positive feeling toward this project group.

4. I am proud to be a member of this project group.

5. I really feel as if this group's problems are my own.

6. This project group has a great deal of personal meaning for me.

\section{Effort Intensity (adapted from [78])}

1. When I work on this project, I do so with intensity.

2. I work at my full capacity in all of my contributions to this project.

3. When I work on this project, I really exert myself to the fullest. 


\section{Goal Commitment (adapted from [78])}

1. I work long hours in this project.

2. I devote a large number of hours to this project.

3. I persist in overcoming obstacles to complete tasks in this project.

\section{Task Performance (adapted from [72])}

1. My contribution to this project is higher than the average in this group.

2. The quality of my contribution is higher than the average in this group.

3. My efficiency of working on this project is much higher than average in this group.

WEILING KE (wke@clarkson.edu) is an associate professor of operations and information systems in the School of Business at Clarkson University. She received her Ph.D. degree from the National University of Singapore. Dr. Ke has been doing research on inter-organizational knowledge sharing, open source software development, e-government development, and enterprise system implementation. She has published in Communications of ACM, International Journal of Electronic Commerce, Decision Support Systems, and Personnel Psychology.

PING ZHANG (Pzhang@syr.edu) is a professor in the School of Information Studies at Syracuse University. She has a Ph.D. from the University of Texas at Austin. Her research interests include human-centeredness in ICT development, evaluation, and use; affective, cognitive, motivational, and behavioral aspects of individual reactions to ICT; and the impact of ICT design and use on individuals, organizations, societies, and cultures. She was co-editor or co-author of three books, co-founding editor-in-chief of AIS Transactions on Human-Computer Interaction, senior editor of Journal of the Association for Information Systems, associate editor of International Journal for Human-Computer Studies and Communications of the Association for Information Studies, and a guest senior editor of special issues of Journal of Management Information Systems, Journal of the Association for Information Systems, International Journal for Human-Computer Studies, International Journal of Human-Computer Interaction, and Behaviour \& Information Technology. 